\title{
A Semi-Random Field Finite Element Method to Predict the Maximum Eccentric Compressive Load for Masonry Prisms
}

\author{
Ehsan Moradabadi ${ }^{1}$, Debra F. Laefer ${ }^{1 *}$, Julie A. Clarke ${ }^{1}$ and Paulo B. Lourenço ${ }^{2}$ \\ ${ }^{1}$ University College Dublin, School of Civil, Structural and Environmental Engineering \\ ${ }^{2}$ ISISE, University of Minho, Department of Civil Engineering \\ * Corresponding Author: Head, Urban Modelling Group, School of Civil, Structural and Environmental \\ Engineering, Newstead, G25, University College Dublin, Dublin 4, IRELAND, Tel/Fax: +353-1-716-3226, \\ debra.laefer@ucd.ie
}

\begin{abstract}
An accurate prediction of the compressive strength of masonry is essential both for the analysis of existing structures and the construction of new masonry buildings. Since experimental material testing of individual masonry components (e.g. masonry unit and mortar joints) often produces highly variable results, this paper presents a numerical modelling based approach to address the associated uncertainty for the prediction of the maximum compressive load of masonry prisms. The method considers numerical model to be semi-random for a masonry prism by adopting a Latin Hyper cube simulation method used in conjunction with a parametric finite element model of the individual masonry prism. The proposed method is applied to two types of masonry prisms (using hollow blocks and solid clay bricks), for which experimental testing was conducted as part of the 9th International Masonry Conference held at Guimarães in July 2014. A Class A prediction (presented before the tests were conducted) was generated for the two masonry prisms according to the proposed methodology, and the results were compared to the final experimental testing results. The root mean square deviation of the method for prediction of eccentric compressive strength of both types of prisms differed by only $2.2 \mathrm{KN}$, thereby demonstrates the potential for this probabilistic approach.
\end{abstract}

Keywords: Masonry Structure, Eccentric compressive strength, Semi-random field finite element, Uncertainty analysis, Latin Hypercube sampling 


\section{Introduction}

Determination of the mechanical behaviour of masonry material is important in order to determine the safety of historical masonry structures and to design new masonry buildings. For many types of masonry structures (e.g. load-bearing walls, vaults, and pillars) the predominant load-carrying ability of masonry is through axial loading in compression. As such, determination of the compressive strength of masonry is crucial to ensure the overall performance for many masonry structures. However, there generally exists some degree of uncertainty in the determination of properties for individual masonry constituents obtained from experimental testing, which is rather high when the properties of the composite are estimated from the properties of the components.

To overcome these limitations, this paper presents a novel methodology for the prediction of the maximum compressive load for masonry prisms. The methodology adopts a probabilistic approach to consider the variation in experimental data for the individual masonry components [1, 2]. This methodology was recently presented at the 9th International Masonry Conference, for which experimental data provided validation. The methodology was applied to produce a Class A prediction [3] for two different prisms; 1) a hollow block masonry prism and 2) a clay brick masonry prism. The two prism types were subsequently tested experimentally to determine the maximum compressive load, allowing for the accuracy of the predicted results to be assessed [1, 2]. This paper presents the proposed method and the detailed outcomes.

\section{Background}

Despite the large quantities of masonry experimental data and the number of theoretical approaches currently available for the estimation of masonry strength under compression, masonry 
material behaviour is not yet fully understood [4]. The need for further research is confirmed by the fact the modern design codes [i.e. EuroCode6 [5] and ACI [6]] employ semi-empirical relations for compressive strength prediction, instead of simplified theoretical approaches [7]. Traditionally masonry compressive strength has been determined by two approaches [8]. The first involves the use of prescribed tables (or analytical expressions) that predict masonry strength based on the individual block strength and mortar type according to empirical formulae [using standards, e.g. EuroCode6]. The second consists of the testing small masonry assemblages either stacked bond prisms with height-to-thickness ratio (h/t) of at least 2 but no greater than 5 or wallettes [5].

The results from experimental testing of masonry assemblages tend to be quite variable due testing conditions, material variability (both block and mortar), and workmanship. Furthermore, multiple prism samples are required to produce a reliable estimation of the masonry stress and stiffness data for use in large-scale structures. Previous experimental tests have demonstrated a high level of uncertainty in the prediction of masonry compressive strength. For example, [9] in the testing of 84 sets of masonry prisms reported a coefficient of variation (COV) of 0.23 for compression strength and 0.34 for the elastic modulus. In a similar study, [4] demonstrated COV values of 0.30 and 0.40 for the compressive strength and elastic modulus, respectively. Kaushik et al. (2007) also reported discrepancies of up to $480 \%$ when various analytical prediction methods $[5,6,10,11]$ were compared to a wide variety of experimental results for brick masonry prisms [9, 12-19]. This same study demonstrated that when mortar strengths were less than 20MPa unconservative errors in excess of $100 \%$ were predicted when analytical equations from current codes are applied [117\% for EuroCode6 [5], and 110\% for ACI [20]].

In an attempt to provide more accurate predictions of the compressive strength of masonry, sophisticated non-linear numerical models have been adopted. Ahmad and Ambrose [8] 
pioneered the use of a three-dimensional (3D) finite element model to study the complex behaviour of hollow block prisms under axial compression. The most significant parameters were found to be mortar type, prism geometry, and bearing plate stiffness; results for concrete masonry prisms were also presented but without experimental validation. By using a homogenised finite element (FE) model, [7] predicted closer experimental outcomes than current codes when considering a wide range of previously reported experimental results [12, 15, 21]. The average absolute error was 32\% for the of the homogenised FE model, 36\% for EuroCode6 [5] and 43\% for ACI [20] and both showed non-conservative estimations for clay bricks [21]. Blackard et al. [22] generated only a 12\% discrepancy with a 3D FE model for a masonry prism consisting of clay bricks and cement mortar under non-eccentric loading, for experimental data with a COV equal to 0.10. However, the estimated peak reached in adopted plane strain method was $41 \%$ higher than the corresponding experimental results. Even when the generalised plane strain was adopted, the peak was $25 \%$ higher than the experimental results. Notably, when tensile cracking is of interest Pina-Henriques and Lourenço [23] advocate adopting meso-scale approaches to incorporate heterogeneity at a lower level and to induce tensile cracking under uniaxial compression.

Overall, the literature review shows that the better estimation is needed to increase the accuracy of material strength of masonry, which could influence the safety and cost issues in assessing relevant structures.

\section{Methodology}

In this study, a probabilistic methodology was adopted for the determination of the maximum compressive load for two types of masonry prism. To do so, a Semi-Random Finite Element Method (SRFEM) was adopted. This method make uses of random field theory [24] to consider 
the variance in the determination of the individual masonry material components (e.g. blocks and mortar joints). Generally, the Random Finite Element Method (RFEM), not available commercially, is an extension of the Finite Element Method that is able to add randomness to all the integration points of the FE model by applying random field theory (i.e. each integration point has randomly a different characteristic in term of material properties) [25]. To simplify the model, a semi-random field concept was applied, and each block or mortar layer was characterised by different material properties.

The methodology used to conduct the semi-random field finite element analysis is illustrated in Figure 1. A parametric finite element model of each prism was initially generated using ABAQUS commercial finite element software [26]. Loading was applied in a quasi-static manner, so as to simulate the loading process that will be adopted in the testing phase. The models were subsequently coupled with a Latin Hypercube Sampling (LHS) algorithm generated in MATLAB [27]. The statistical distribution of each material property was determined according to the experimental results, provided before masonry prism testing [1, 2]. The parametric models were subsequently conducted which simulated the arbitrary sets of material properties. Plasticity parameters for the applied constitutive law were calibrated with experimental test results, again provided before masonry prism testing. A stochastic analysis was then conducted and the maximum compressive load for each prism was determined according to the results of the probabilistic analysis. 


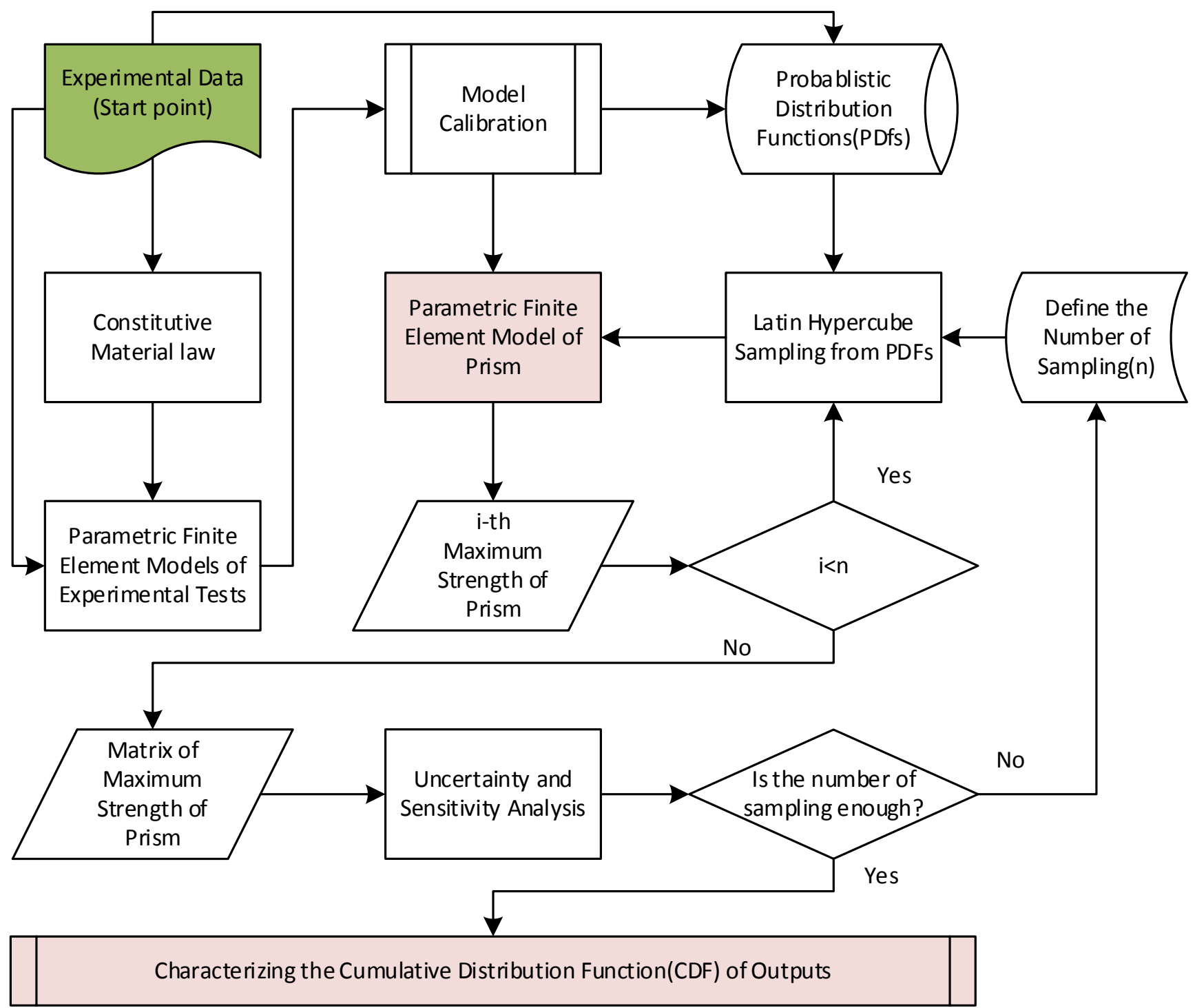

Figure 1. Semi-random field finite element analysis methodology 
Two sets of eccentric loading tests (three tests for each type) were carried out 240 days after construction of the masonry specimens, allowing for an assessment of the accuracy of the numerical prediction. Figure 2 shows the geometry of the specimens and the location of the applied loading where additional information regarding the experimental testing may be found in [1, 2]. 


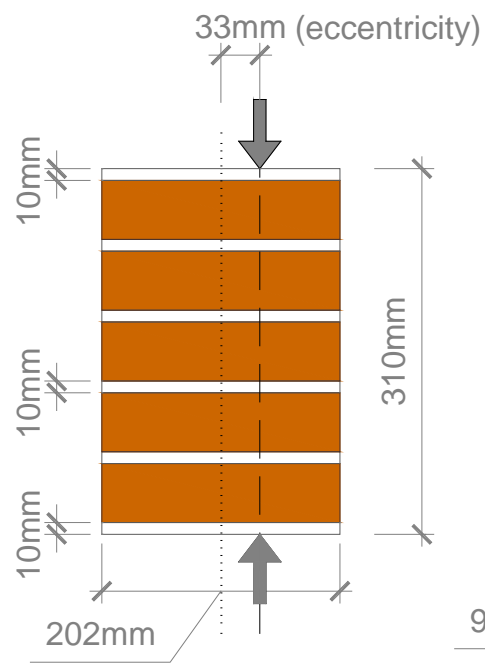

a)

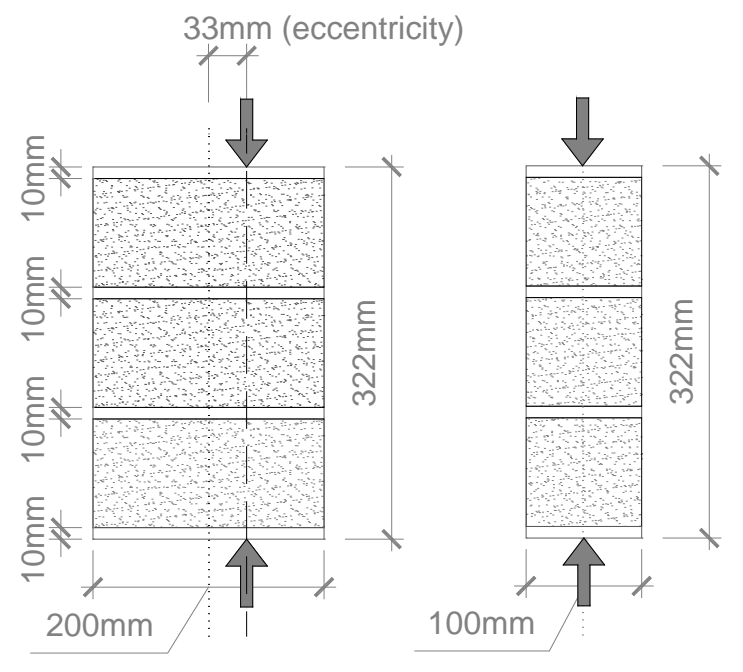

b)

Figure 2. The geometry of specimens with eccentric load application: a) brick prisms (front and lateral view); and b) concrete hollow prisms (front and lateral view) 


\subsection{Material Constitutive Law}

A continuum plasticity-based damage model [28] was adopted for defining the failure behaviour of each component of the masonry prisms (i.e. bricks, mortar layers and concrete hollow blocks). This material model assumes that the main two failure mechanisms of the brittle material are tensile cracking and compressive crushing. The evolution of the yield (or failure) surface is controlled by two hardening variables, the tensile equivalent plastic strain, $\widetilde{\boldsymbol{\varepsilon}}_{\boldsymbol{t}}^{\boldsymbol{p l}}$, and the compressive equivalent plastic strain, $\widetilde{\boldsymbol{\varepsilon}}_{\boldsymbol{c}} \boldsymbol{p l}$, which are linked to the failure mechanisms under loading. The model assumes that the uniaxial tensile and compressive response of the material is characterized according to a softening law, as illustrated in Figure 3.

Under uniaxial tension, the stress-strain response follows a linear elastic relationship until the value of the failure stress, $\sigma_{t 0}$, is reached. The failure stress corresponds to the onset of microcracking in the material. Beyond this stress level, the formation of micro-cracks is represented macroscopically by a stress-strain softening response, which induces strain localization in the material structure. Under uniaxial compression, the material response is linear until initial yield is reached, $\sigma_{c 0}$. In the plastic regime the material response is typically characterized by stress hardening followed by strain softening beyond the ultimate stress, $\sigma_{c u}$. This representation, although somewhat simplified, captures the main features of the response of masonry. There is also an assumption that the uniaxial stress-strain curves can be converted into stress versus plasticstrain curves (this conversion is performed automatically by ABAQUS from the user-provided stress versus “inelastic” strain data). 

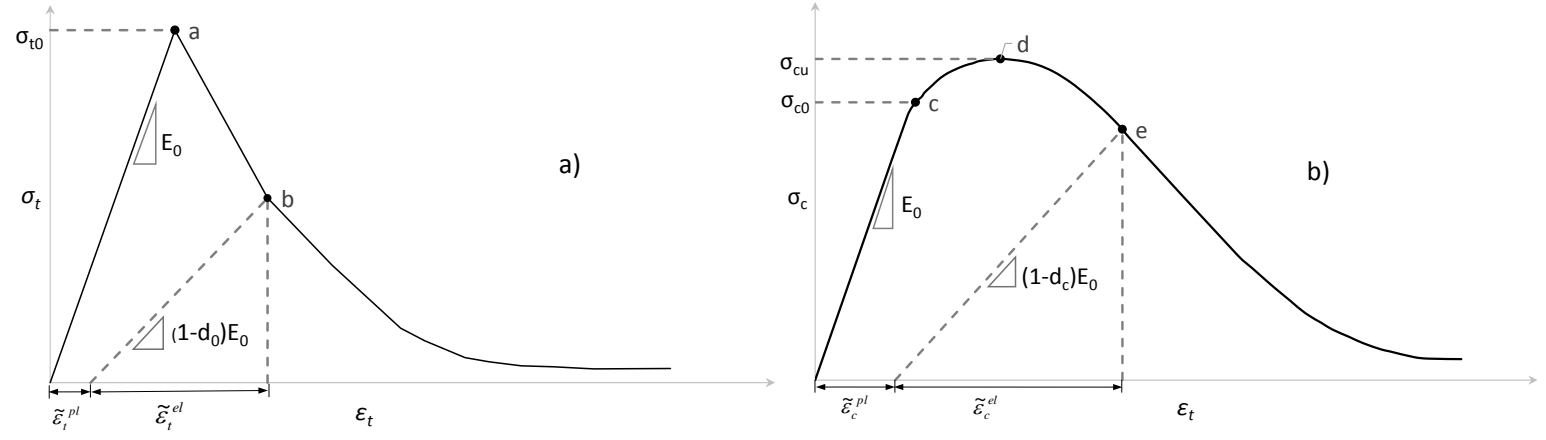

Figure 3. Response of masonry to uniaxial loading in tension (a) and compression (b) [28] 


\subsection{Stochastic Analysis}

Experimental results of compression tests and flexural tests all masonry components reported herein were provided by [1, 2]. To implement this data in a stochastic analysis, the results of each material experiment were fitted to the constitutive law described in previous section. Figures 4 and 5 illustrate the stochastic analysis of the compressive strength of brick masonry samples and concrete hollow blocks, respectively, for use with a plasticity-based damage model where a summary of the material properties is provided in a separate tables (Table 1 and 2) and , where mu indicates the average value. The stress-strain curve for each sample was divided into three separate material zones of behaviour: (1) linear behaviour as indicated by the compression initial yield value, $\sigma_{c 0}$ and the corresponding strain, ec, (2) pre-failure inelastic behaviour as indicated by the ultimate compression yield value, $\sigma_{c u}$ and the corresponding strain, $e_{d}$, and (3) post-failure inelastic behaviour as indicated by a stress of 20MPa in the post-failure region, ee. In other words, the material constitutive law for each sample was approximated with 3 critical points(c, d and e which were defined in Figure 3) and the summary of results were provided for statistical analysis. In both cases of brick and hollow concrete blocks, the coefficient of determination, R-square value, of the linear region of material behaviour was in excess of 0.95, which demonstrates the high level of appropriateness of the applied regression procedure. Due to complexity of mortar behaviour, the R-square value for linear part of mortar samples under compression were less than brick and hollow concrete block. However, as the value was more than 0.89 for all samples, a similar procedure was followed for the mortar sample data, as presented in Figure 6 and Table 3. 


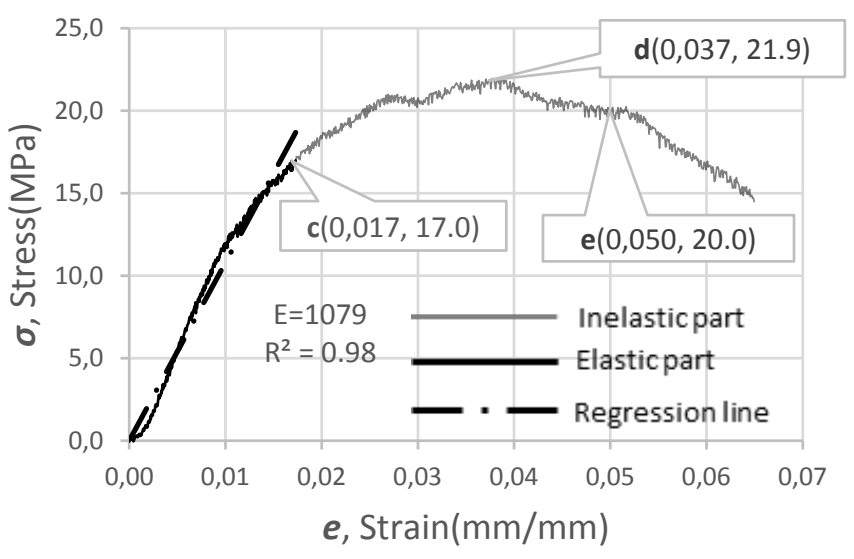

a)

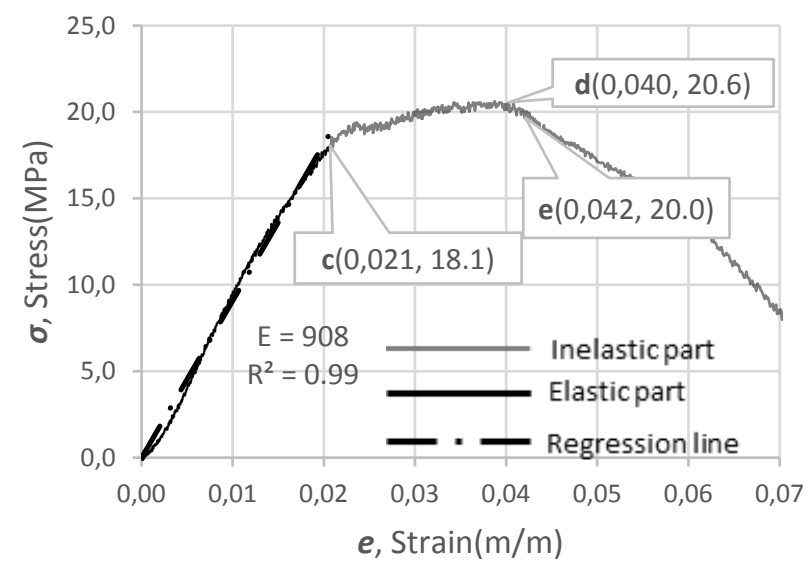

c)

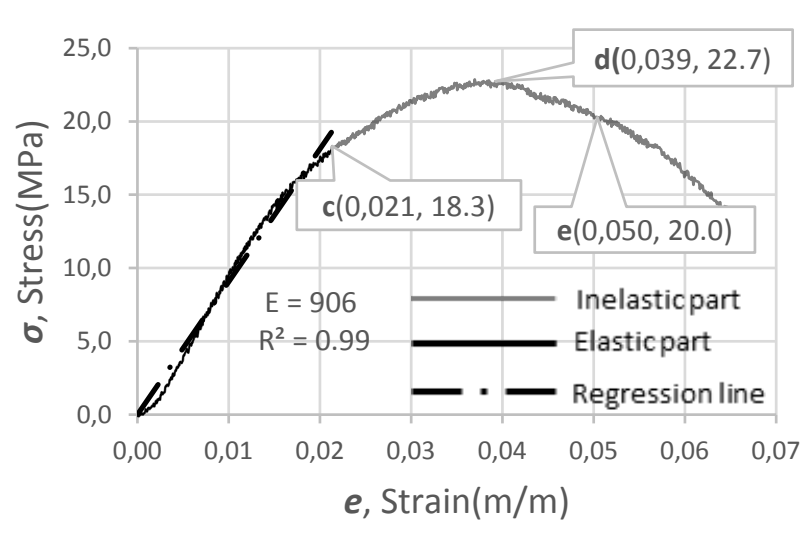

b)

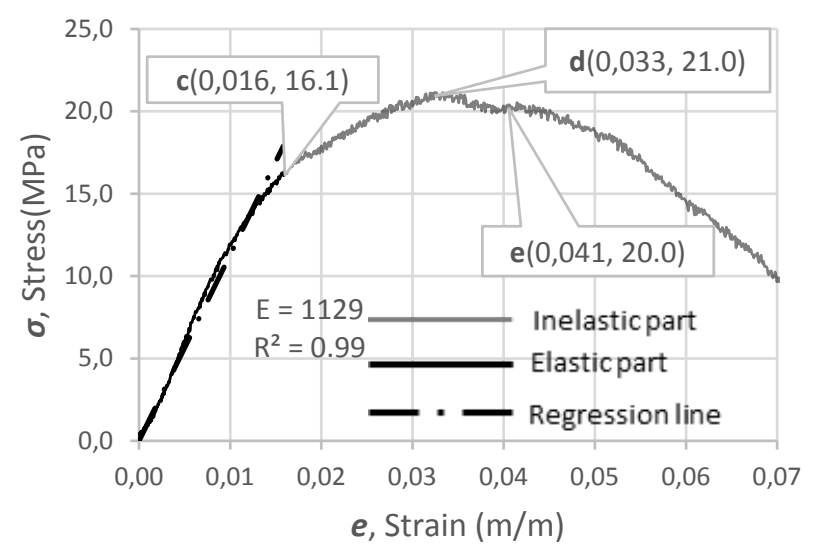

d)

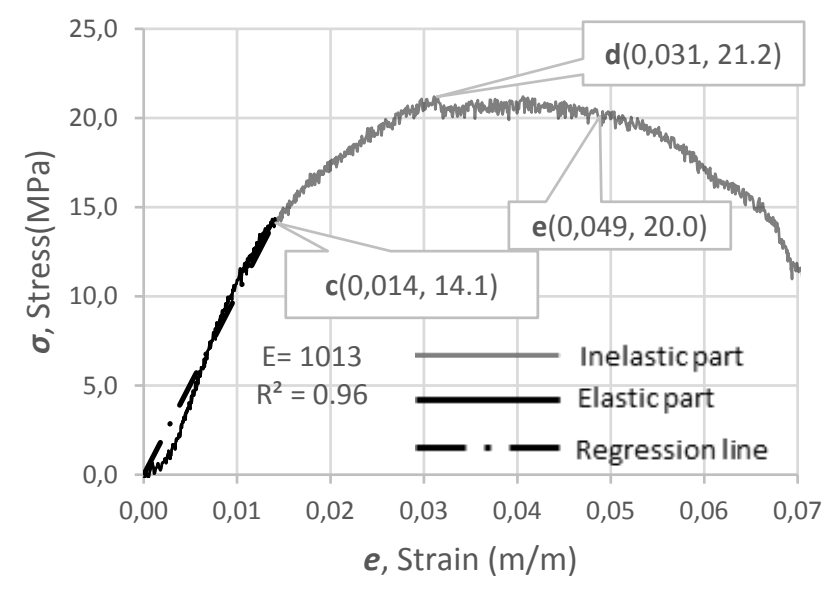

e)

Figure 4. Stochastic analysis of compressive data for different brick masonry samples: a) SCB.C1, b) SCB.C2, c) SCB.C3, d) SCB.C4, e) SCB.C4 
Table 1- Summary of results for stochastic analysis of compressive data for different brick masonry samples

\begin{tabular}{ccccccc} 
Sample & $\begin{array}{c}\sigma_{C 0} \\
(\mathrm{MPa})\end{array}$ & $e_{\boldsymbol{c}}$ & $\begin{array}{c}\sigma_{\mathrm{Cu}} \\
(\mathrm{MPa})\end{array}$ & $e_{\boldsymbol{d}}$ & $e_{\boldsymbol{e}}$ & $\begin{array}{c}\mathrm{E} \\
(\mathrm{MPa})\end{array}$ \\
\hline SCB.C1 & 17.0 & 0.02 & 21.9 & 0.04 & 0.05 & 1079 \\
SCB.C2 & 18.3 & 0.02 & 22.7 & 0.04 & 0.05 & 906 \\
SCB.C3 & 18.1 & 0.02 & 20.6 & 0.04 & 0.04 & 908 \\
SCB.C4 & 16.1 & 0.02 & 21.0 & 0.04 & 0.04 & 1129 \\
SCB.C5 & 14.1 & 0.01 & 21.2 & 0.03 & 0.05 & 1013 \\
$\mu$ & 16.7 & 0.02 & 21.5 & 0.04 & 0.05 & 1007 \\
COV & 0.08 & 0.21 & 0.03 & 0.10 & 0.09 & 0.08 \\
* The strain corresponds to a stress of 20MPa & & & &
\end{tabular}




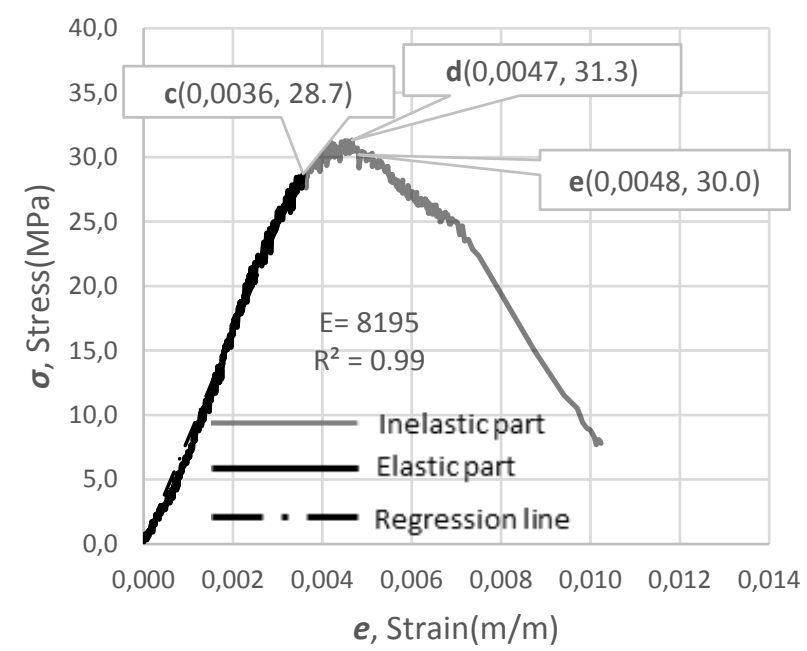

a)

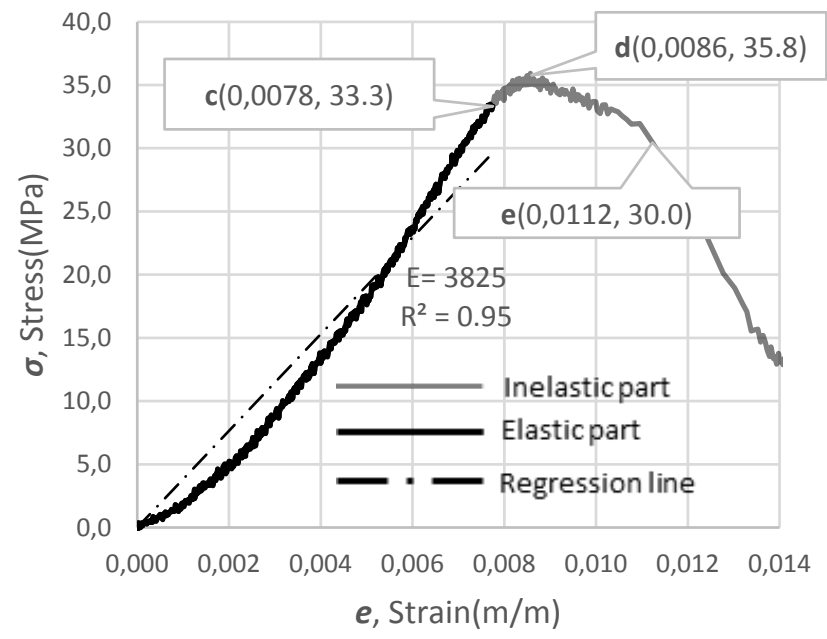

c)

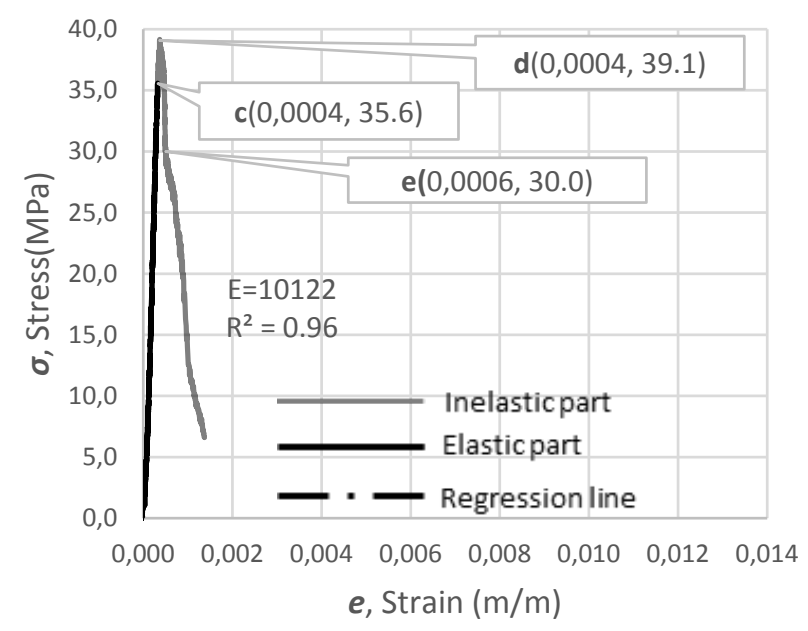

b)

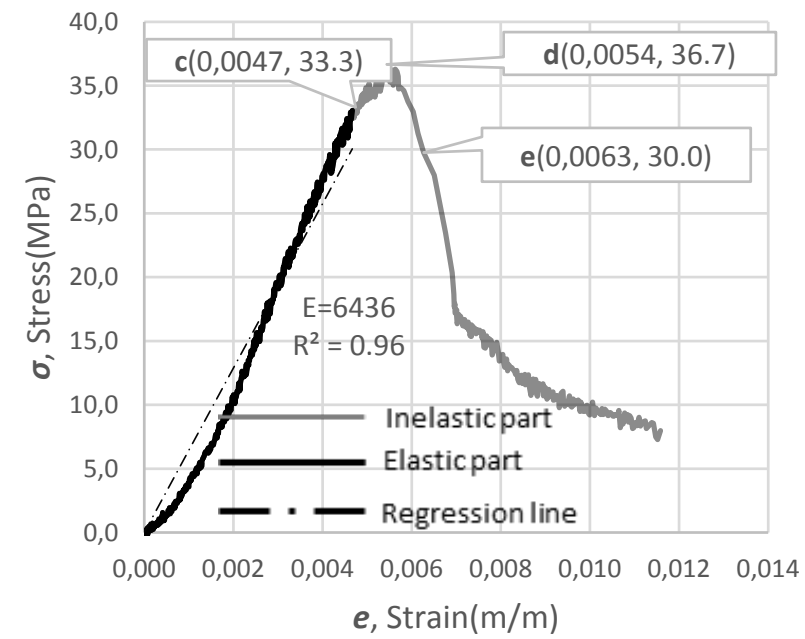

d)

Figure 5. . Stochastic analysis of concrete hollow block compressive data: a) HCB.C2, b) HCB.C3, c) HCB.C4, d) HCB.C5 
Table 2- Summary of results for stochastic analysis of concrete hollow block compressive data

\begin{tabular}{ccccccc} 
Sample & $\begin{array}{c}\sigma_{\mathrm{C} 0} \\
(\mathrm{MPa})\end{array}$ & $e_{\boldsymbol{c}}$ & $\begin{array}{c}\sigma_{\mathrm{Cu}} \\
(\mathrm{MPa})\end{array}$ & $e_{\boldsymbol{d}}$ & $e_{\boldsymbol{e}}{ }^{*}$ & $\begin{array}{c}\mathrm{E} \\
(\mathrm{MPa})\end{array}$ \\
\hline HCB.C2 & 28.7 & 0.0036 & 31.3 & 0.0047 & 0.0048 & 8195 \\
HCB.C3 & 35.6 & 0.0004 & 39.1 & 0.0004 & 0.0006 & 10122 \\
HCB.C4 & 33.3 & $\mathbf{0 . 0 0 7 8}$ & 35.8 & $\mathbf{0 . 0 0 8 6}$ & 0.0112 & $\mathbf{3 8 2 5}$ \\
HCB.C5 & 33.3 & 0.0047 & 36.7 & 0.0054 & 0.0063 & 6436 \\
$\mu$ & 32.7 & 0.0041 & 35.7 & 0.0062 & 0.0057 & 7144 \\
COV & 0.07 & 0.57 & 0.07 & 0.25 & 0.58 & 0.29
\end{tabular}

*The strain corresponds to stress of 30MPa

Bolded data are outliers, and they are used to indicate the probable upper bounds or lower bounds of the corresponding probabilistic distribution functions 


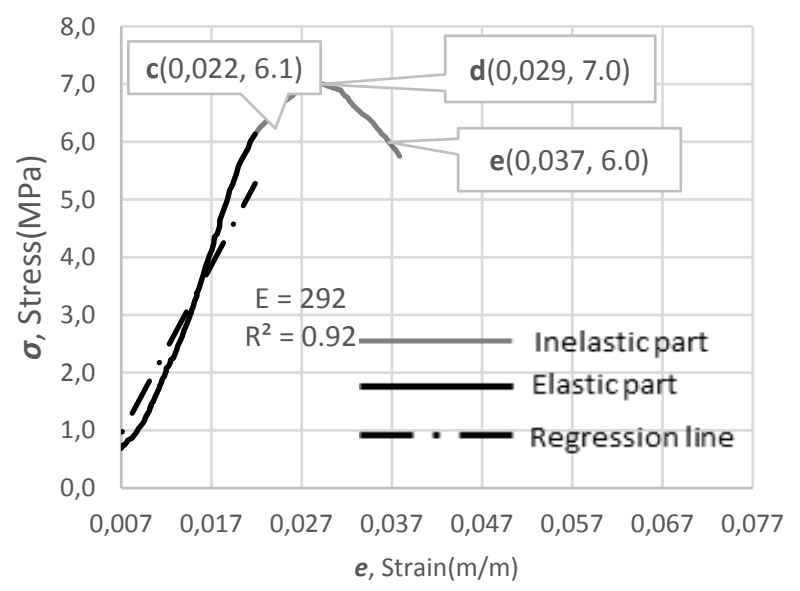

a)

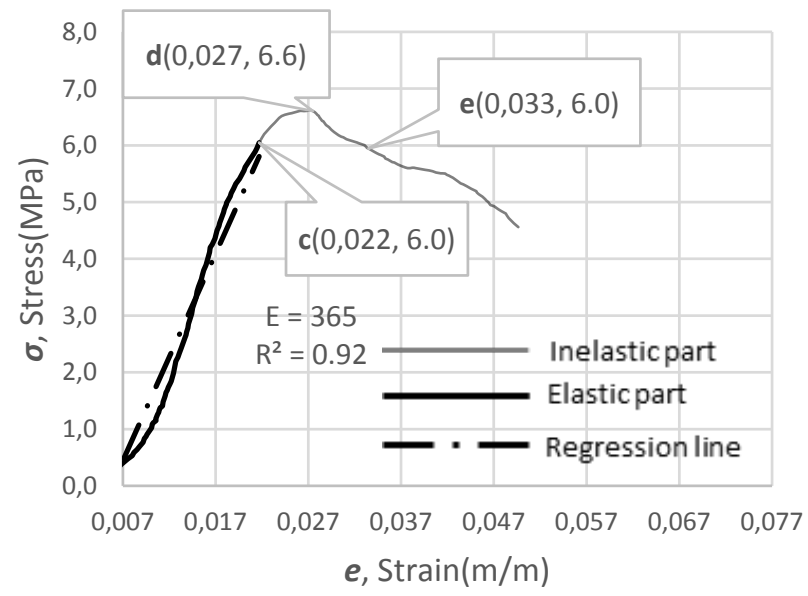

c)

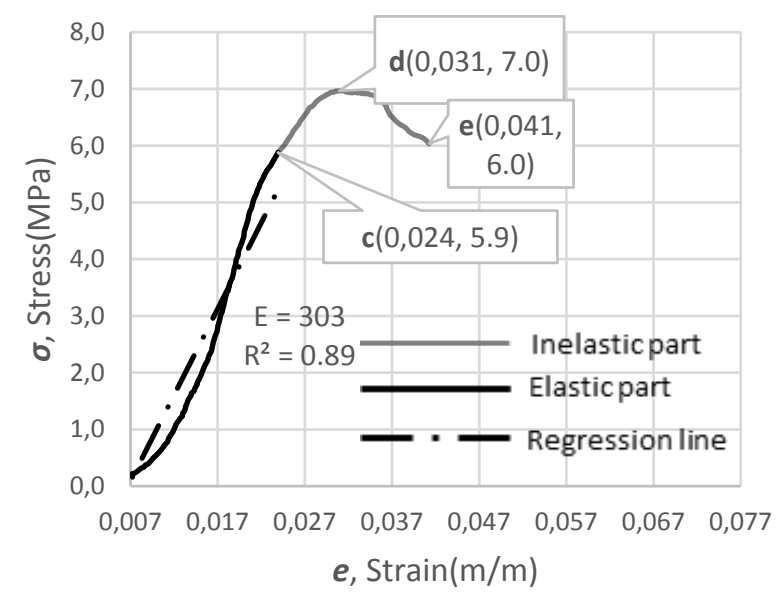

b)

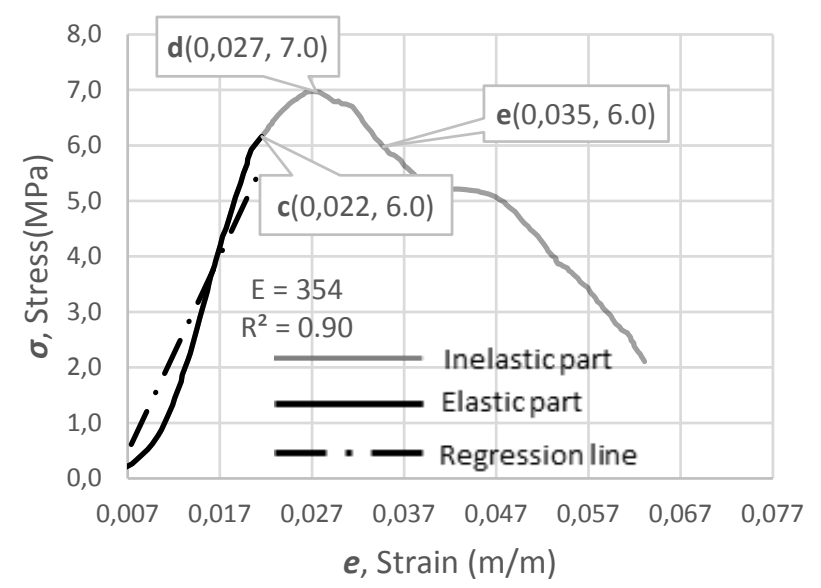

d)

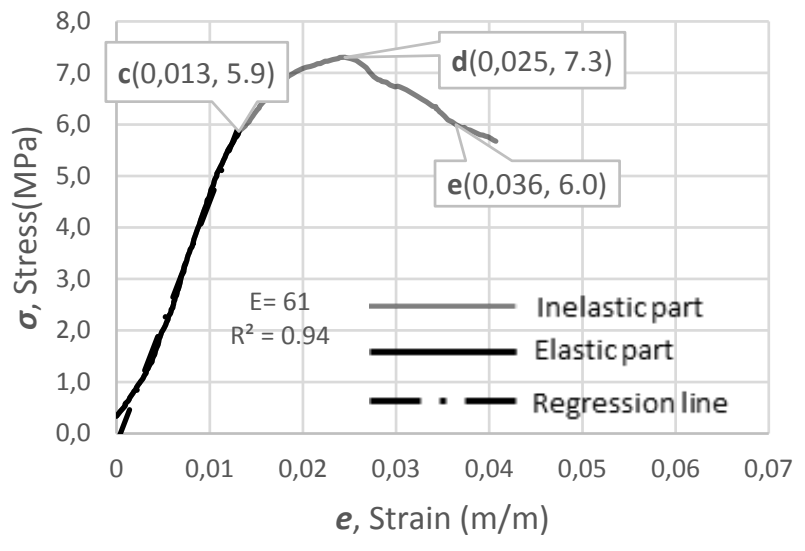

e)

Figure 6. Stochastic analysis of mortar sample compressive data: a) MS.C7, b) MS.C8, c) MS.C9, d) MS.C10, e) MS.C11 
Table 3- Summary of results for analysis of mortar sample compressive data

\begin{tabular}{ccccccc} 
Sample & $\begin{array}{c}\sigma_{\mathrm{CO}} \\
(\mathrm{MPa})\end{array}$ & $e_{\boldsymbol{c}}$ & $\begin{array}{c}\sigma_{\mathrm{Cu}} \\
(\mathrm{MPa})\end{array}$ & $e_{\boldsymbol{d}}$ & $e_{\boldsymbol{e}}$ & $\begin{array}{c}\mathrm{E} \\
(\mathrm{MPa})\end{array}$ \\
\hline MS.C7 & 6.1 & 0.022 & 7.0 & 0.029 & 0.037 & 292 \\
MS.C8 & 5.9 & 0.024 & 7.0 & 0.031 & 0.041 & 303 \\
MS.C9 & 6.0 & 0.022 & 6.6 & 0.027 & 0.033 & 365 \\
MS.C10 & 6.0 & 0.022 & 7.0 & 0.027 & 0.035 & 354 \\
MS.C11 & 5.9 & 0.013 & 7.3 & 0.025 & 0.036 & $\mathbf{6 1}$ \\
$\mu$ & 6.0 & 0.021 & 7.0 & 0.028 & 0.036 & 275 \\
COV & 0.01 & 0.11 & 0.03 & 0.08 & 0.07 & 0.40
\end{tabular}

*The strain corresponds to stress of $6 \mathrm{MPa}$

Bolded data are outliers, and they are used to indicate the probable upper bounds or lower bounds of the corresponding probabilistic distribution functions 
Figures 7, 8 and 9, respectively illustrate the results for the brick samples, concrete hollow block samples and mortar samples respectively. According to the data provided [1, 2], the flexural elastic modules of specimens were determined by using the 3-point bending test's classic formula (i.e. $E=\frac{F}{\delta} \frac{L^{3}}{4 b d^{3}}$, which $F$ is the maximum load applied to the beam, $\delta$ is the maximum deflection corresponding to $F, L$ is the length of specimen, b is the width, and d is the depth of specimen's section). The flexural strength of samples, $\sigma f$, were derived by using approximate classic failure formula (i.e. $\sigma_{f}=1.5 \frac{F L}{b d^{2}}$ ). Tables 4 to 6 summarise these calculations for different samples.

A comparison of the results from the flexural test and the compression tests demonstrated a close match for both the concrete hollow blocks and the mortar samples. However, for the brick samples, the results differed. Thus, the Young's modulus of the bricks derived from the flexural testing was not adopted herein. Instead, they were used to determine the ultimate tensile strength value of the brick masonry. 


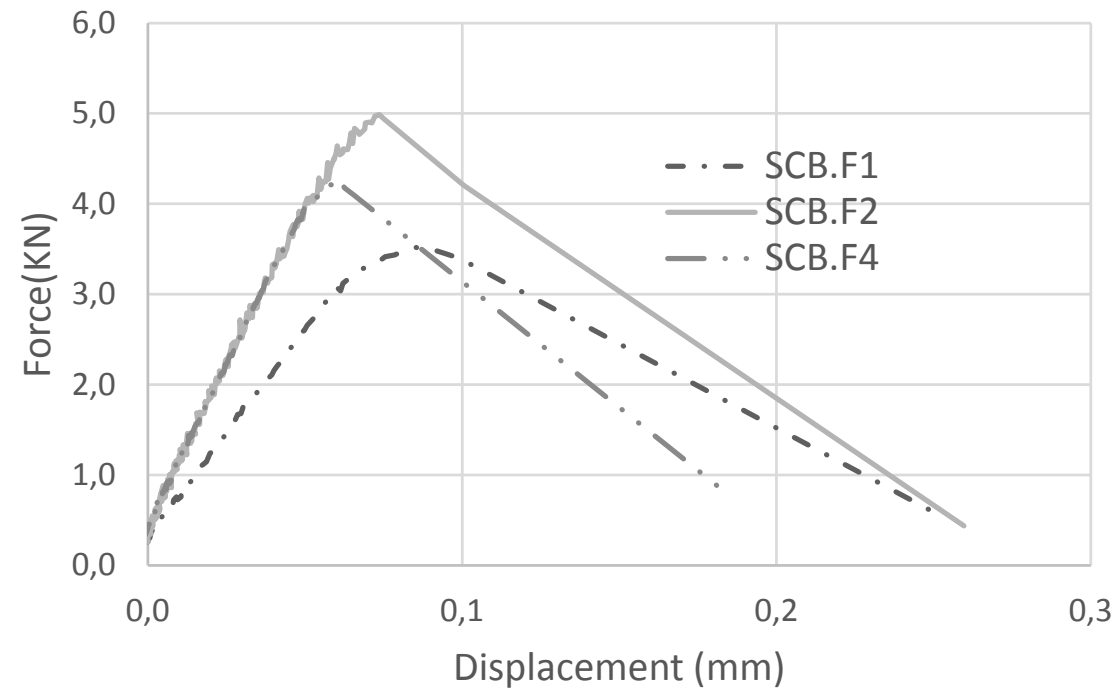

Figure 7. Stochastic analysis of the brick samples' flexural data: Force-Displacement Diagram 
Table 4- Summary of flexure results for brick samples

\begin{tabular}{lccc} 
Sample & $F_{f}(\mathrm{KN})$ & $\sigma_{f}(\mathrm{MPa})$ & $\begin{array}{c}\mathrm{E} \\
(\mathrm{MPa})\end{array}$ \\
\hline SCB.F1 & 3.5 & 3.2 & 3705 \\
SCB.F2 & 5.0 & 3.6 & 6052 \\
SCB.F4 & 4.2 & 3.1 & 6274 \\
$\mu$ & 4.2 & 3.3 & 5344 \\
COV & 0.12 & 0.12 & 0.19
\end{tabular}


Figure 8. Stochastic analysis of the concrete hollow blocks' flexural data: ForceDisplacement Diagram

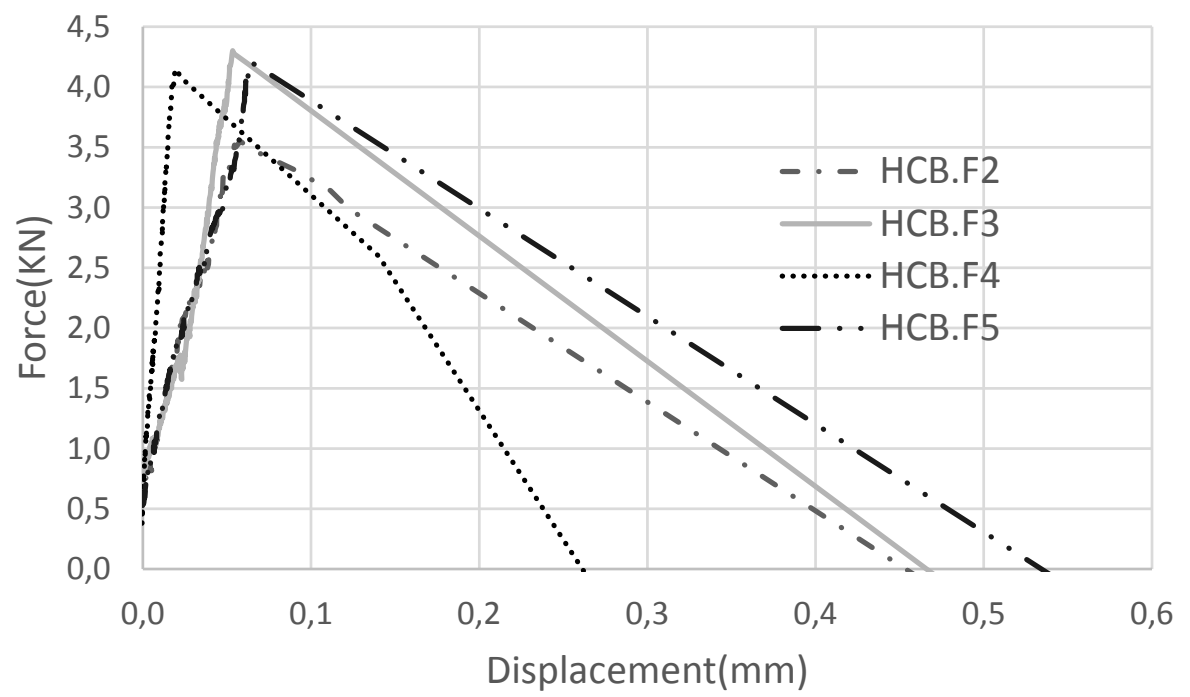


Table 5. Summary of results for hollow blocks' flexural data

\begin{tabular}{cccc} 
Sample & $\mathrm{F}_{\mathrm{f}}(\mathrm{KN})$ & $\sigma_{\mathrm{f}}(\mathrm{MPa})$ & $\begin{array}{c}\mathrm{E} \\
(\mathrm{MPa})\end{array}$ \\
\hline HCB.F2 & 3.6 & 5.8 & 6384 \\
HCB.F3 & 4.3 & 7.0 & 8340 \\
HCB.F4 & 4.2 & 6.6 & 2140 \\
HCB.F5 & 4.2 & 6.7 & 6948 \\
$\mu$ & 4.1 & 6.5 & 5953 \\
COV & 0.07 & 0.07 & 0.40
\end{tabular}




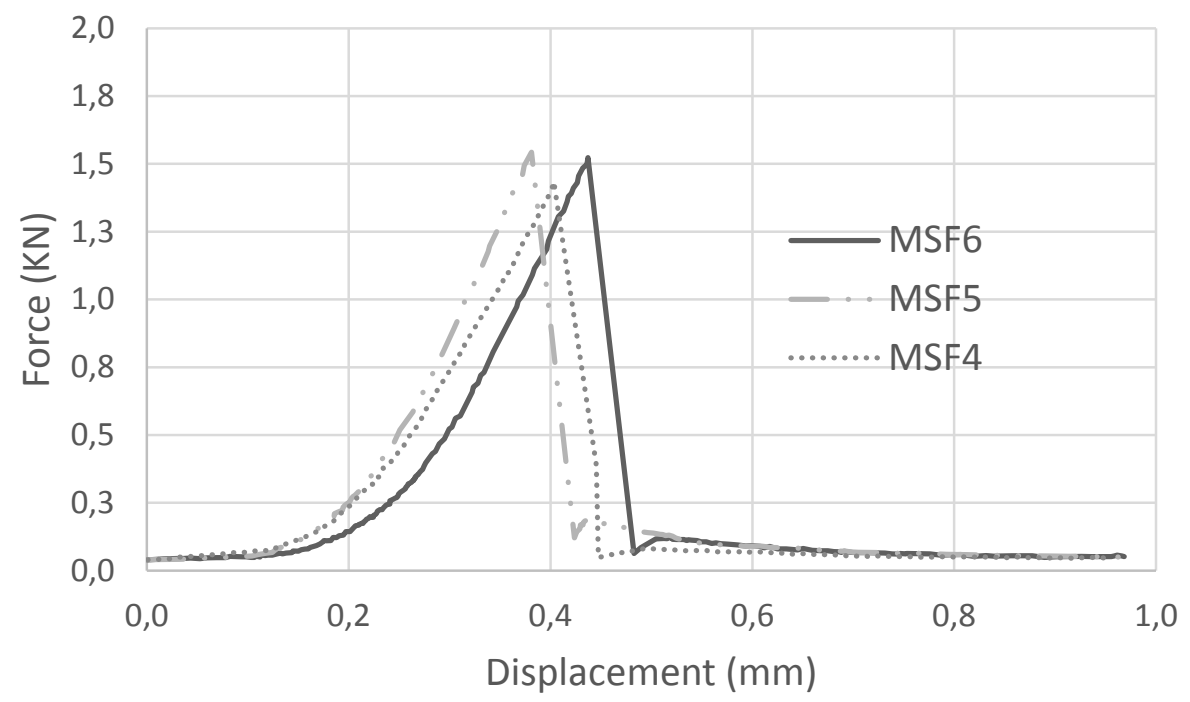

Figure 9. Stochastic analysis of the mortar samples' flexural data: Force-Displacement Diagram 
Table 6 - Summary of results for mortar samples’ flexural data

\begin{tabular}{cccc} 
Sample & $\mathrm{F}_{\mathrm{f}}(\mathrm{KN})$ & $\sigma_{\mathrm{f}}(\mathrm{MPa})$ & $\begin{array}{c}\mathrm{E} \\
(\mathrm{MPa})\end{array}$ \\
\hline MS.F4 & 1.5 & 3.4 & 340 \\
MS.F5 & 1.6 & 3.7 & 395 \\
MS.F6 & 1.6 & 3.6 & 347 \\
$\mu$ & 1.6 & 3.6 & 361 \\
COV & 0.03 & 0.03 & 0.07
\end{tabular}




\subsection{Parametric 3D Finite Element Model}

The two masonry prisms outlined in Figure 2 were numerically simulated using the commercial finite element software, ABAQUS Version 6.10. A MATLAB code was subsequently generated to parameterize the model. The brick masonry prism and concrete hollow prism models consisted of 9,000 and 7,059 first order hexahedral elements (C3D8R), respectively. These corresponded to models of 32,577 and 39,690 model degrees of freedom (DOF). An eccentric, quasi-static loading was applied to each model using an explicit step function with linear amplitude, in order to apply a concentrated point load. To adopt a semi-random field criterion, each material layer was assigned identifiable material properties. Figure 10 illustrates the threedimensional (3D) models, and Figure 11 demonstrates the deformed mesh, along with the equivalent plastic strains for each model for an arbitrarily selected set of material properties. 


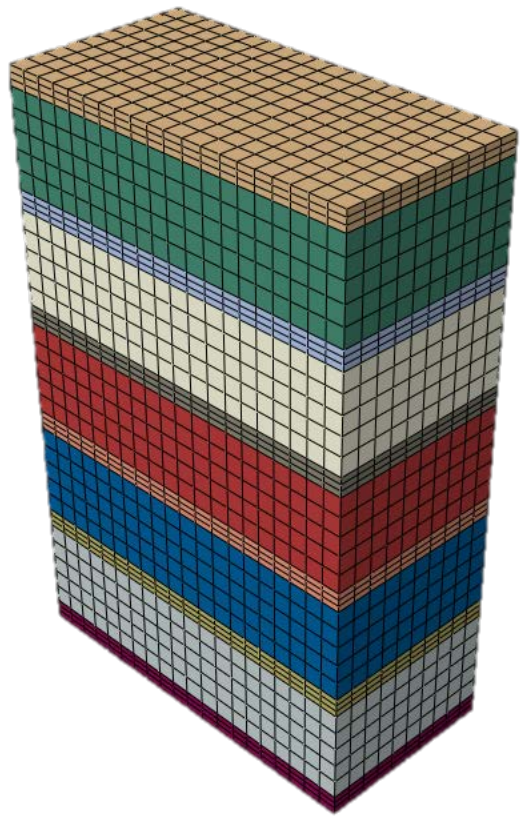

a)

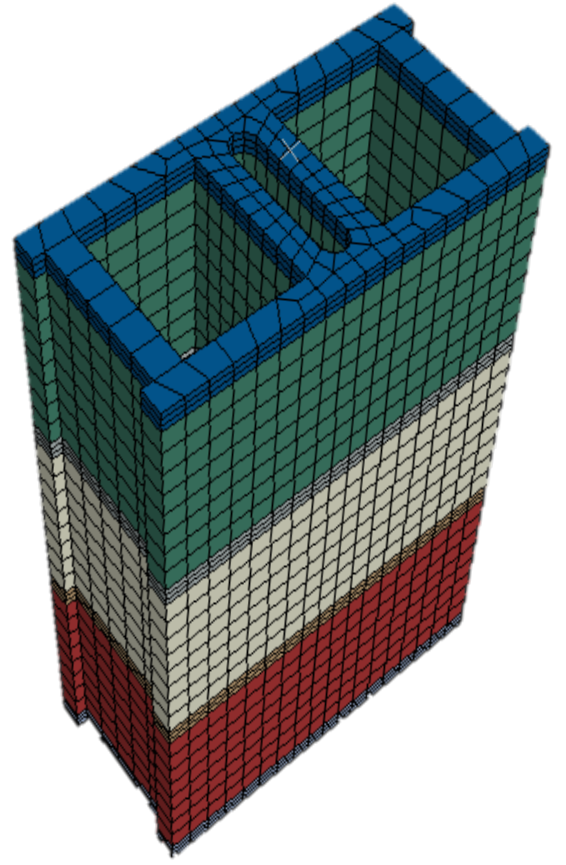

b)

Figure 10. Finite Element 3D Model: a) Brick prism, b) Concrete hollow prism

(Variation in colour indicates different material properties) 
Figure 11 illustrates the lateral "bursting”, which occurred under loading for arbitrarily selected material properties. This material phenomenon was concentrated in the mortar layers and the lower blocks of the brick prism and reflected the non-symmetric distribution of material properties occurring in the semi-random field concept. For the concrete hollow prism, the bursting was concentrated in the mortar layers of the prism, particularly in the lower layer. 


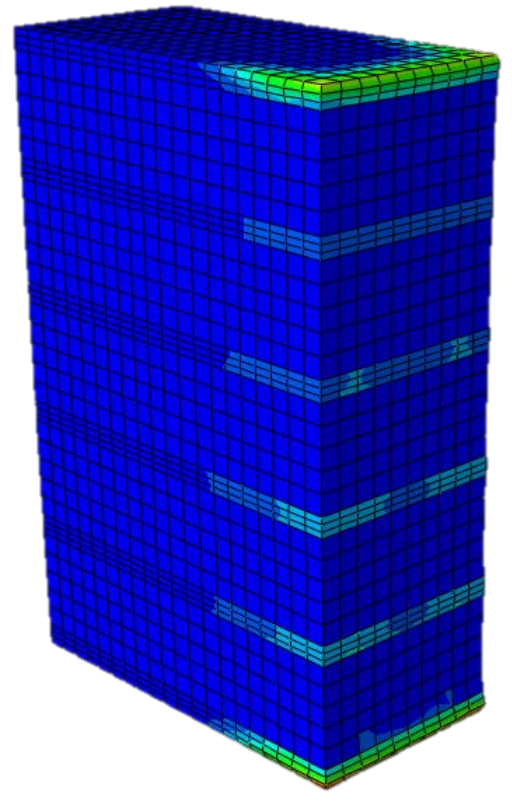

a)
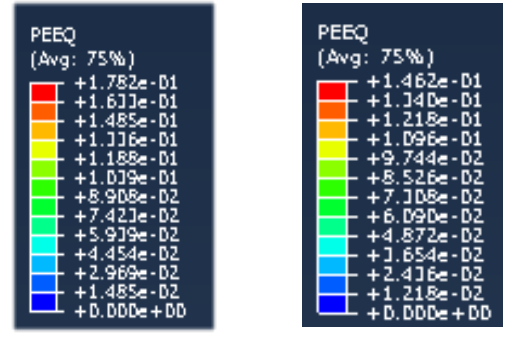

b)

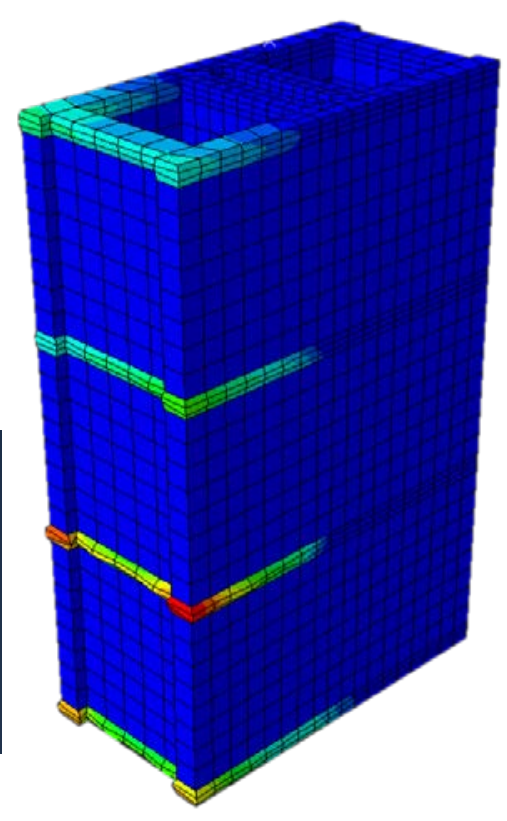

Figure 11. Distribution of principal equivalent plastic strain (PEEQ) at the integration points upon failure: a) Brick prism, b) Concrete hollow prism 


\subsection{Numerical Model Calibration}

Since a damage-plasticity constitutive law was utilised in ABAQUS, which assumes a continuum material behaviour, simulation of the prisms according to the raw data provided may have introduced inaccuracies. Therefore, to help ensure that the numerical model closely represented the experimental behaviour, three numerical models were initially conducted for which the numerical material behaviour was back-calibrated against the previously analysed, experimental data.

This was done using three parameters related to the damage-plasticity model: dilation angle, flow potential eccentricity, and ratio of initial equi-biaxial compressive yield stress to the initial uniaxial compressive yield stress ( $\mathrm{fb} 0 / \mathrm{fc} 0$ ). The analyses were conducted for a variety of values of these three parameters until a match with the experimental results was achieved. Figure 12 illustrates a comparison between the calibrated numerical results and the actual material behaviour for the concrete hollow blocks. Since post-failure behaviour of the specimens was not of interest in this study, the adoption of a perfectly plastic, post-yield material response in compression was considered acceptable, and provided faster convergence of the non-linear process. 


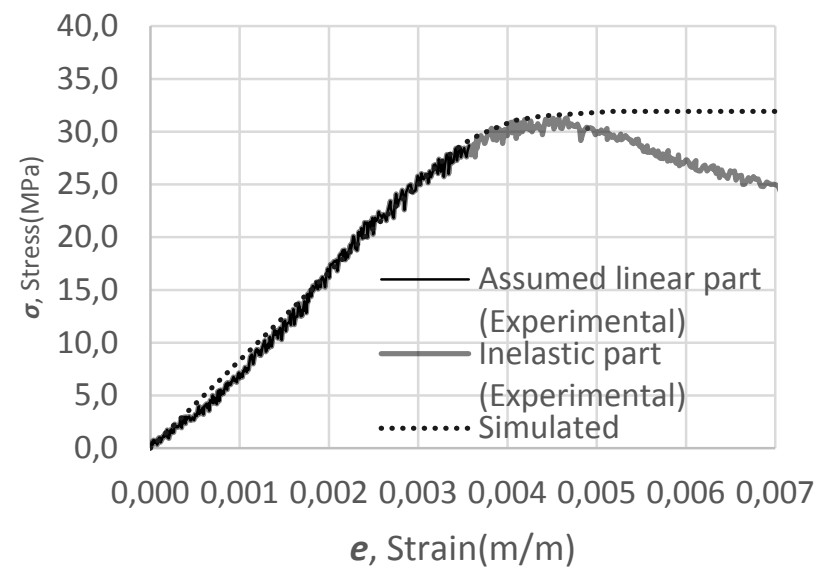

a)

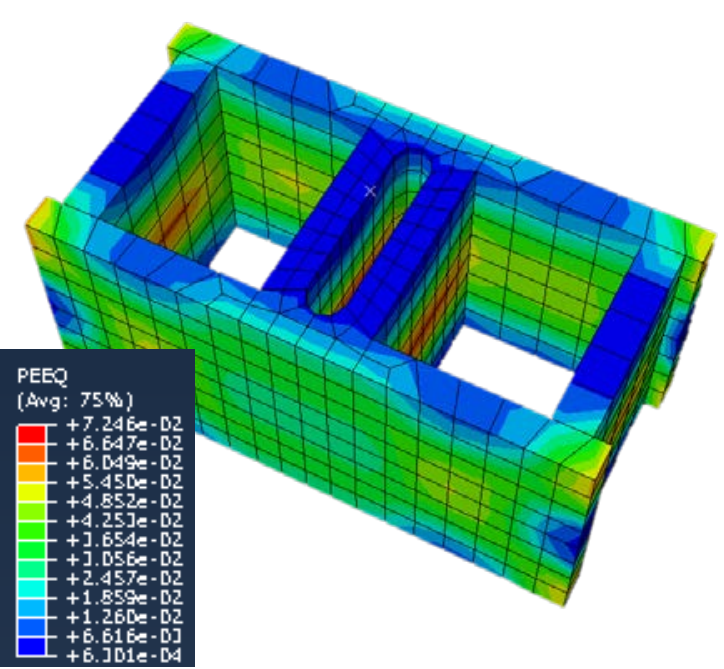

b)

Figure 12.Numerical results for calibration the compression test of hollow concrete block (specimen HCB-C2): a) Comparison of simulation results with experimental data, b) Distribution of principal equivalent plastic strain (PEEQ) at the integration points during failure 
This procedure was also adopted for the brick and mortar samples. Figure 13 demonstrates the comparison between the numerically predicted and experimentally established material behaviours for the brick sample, as well as the distribution of principal equivalent plastic strain (PEEQ) at the integration points.

Behaviour of the mortar samples is particularly complex as it is highly dependent on the variation of the Poisson's ratio during loading and failure [29]. To simplify the model to derive satisfactory results, the mortar layer was also fitted to the damage plasticity model. Moreover, to consider the general effect of the Poisson's ratio, a probabilistic function with uniform distribution considering the lower bound and upper bound was adopted in the parametric model for Poisson's ratio relevant to uncertain value of stress/strain ratio during failure [29]. Simulation results for a mortar specimen are illustrated in Figure 14. Since the predominant failure mode in prism tests was compression and since the preliminary results showed that none of integration points in FEM reached to tension plastic strain during failure of prisms, the calibration of flexural test was not conducted. 


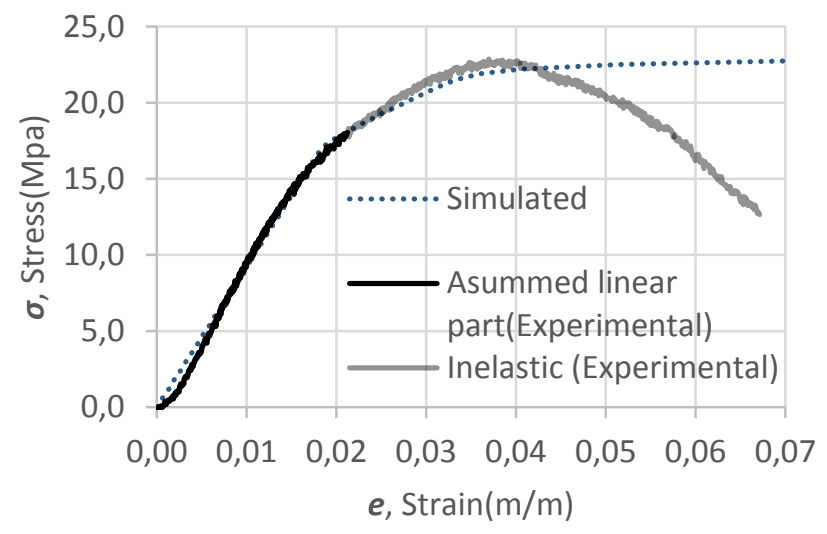

a)

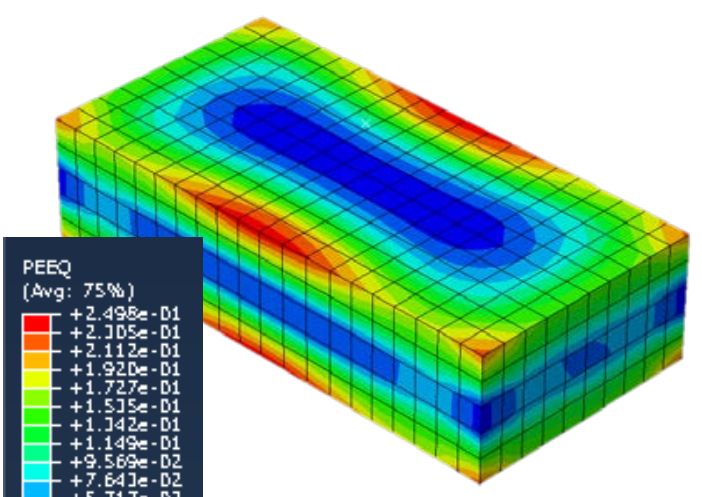

b)

Figure 13. Numerical results for calibration the compression test of brick (specimen SCB-C2): a) Comparison of Simulation results with experimental data, b) Distribution of principal equivalent plastic strain (PEEQ) at the integration points during failure 


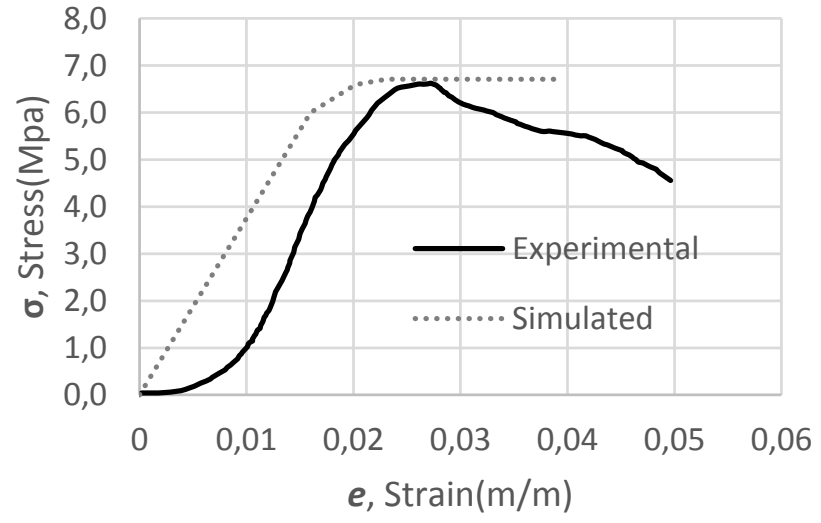

a)

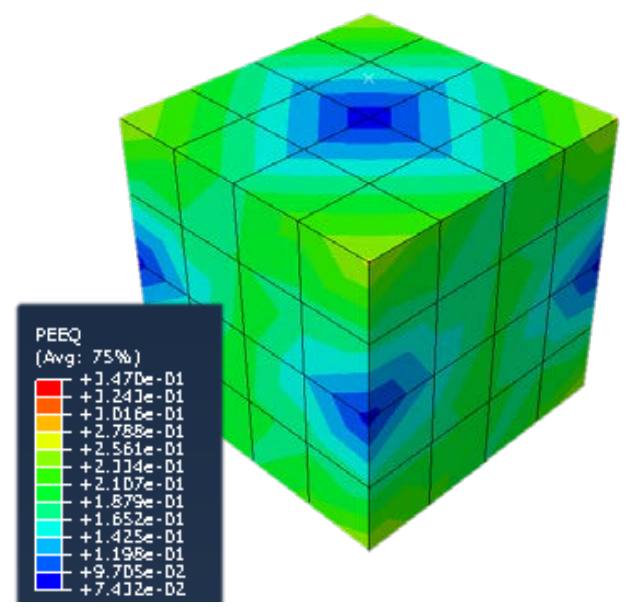

b)

Figure 14. Numerical results for calibration the compression test of mortar (specimen MS.C9) a) Comparison of simulation results with experimental data, b) Distribution of principal equivalent plastic strain (PEEQ) at the integration points during failure 


\subsection{Latin Hypercube Sampling Algorithm}

The assessment and presentation of the effects of uncertain input variables for a complex system can be recognized simply by the following equation:

$$
Y_{i}=f\left(X_{i}\right)
$$

where the function $\boldsymbol{f}$ represents the model under investigation, $X_{i}=\left[X_{i 1}, x_{i 2}, \ldots, x_{i n}\right]$ is a vector of model inputs, and $Y_{i}=\left[y_{i 1}, y_{i 2}, \ldots, y_{i n}\right]$ is a vector of model predictions. In this paper, $x_{i n}$ s are the material properties (e.g. Young's modulus, Poisson's ratio, yield stress, etc.) where ' $i$ ' represents the prism type (i=1 for brick masonry prism and $\mathrm{i}=2$ for concrete hollow masonry prism), respectively, and $y_{\text {in }}($ with $\mathrm{n}=1$ ) is the maximum compressive load of the model.

The goal of the uncertainty analysis was to determine the uncertainty in the elements of $\boldsymbol{Y}$ that arose from the uncertainty in the elements of $\boldsymbol{X}$ [7]. In this paper, $\boldsymbol{f}$ is quite complex, as demonstrated in the parametric ABAQUS model generated in the previous section using MATLAB. To conduct the uncertainty analyses through the parametric FE model based on experimental data, characterization of the uncertainty in the input variables was required. In this case, the uncertainty in the elements of $\boldsymbol{X}$ was assumed to be characterized by a sequence of distributions:

$$
D_{1}, D_{2}, \ldots, D_{n_{X}}
$$

where $\boldsymbol{D}_{\boldsymbol{j}}$ is the distribution associated with the element $\boldsymbol{x}_{\boldsymbol{j}}$ of $\boldsymbol{X}$ and $\boldsymbol{n} \boldsymbol{X}$ is the number of elements contained in $\boldsymbol{X}$ (i.e., $\boldsymbol{X}=\left[\boldsymbol{x}_{1}, \boldsymbol{x}_{2}, \ldots, \boldsymbol{x}_{n X}\right]$ ). The various distribution functions adopted in this analysis are presented in Table 7. For notational convenience and also for the ease of 
presentation, the distributions in Eq. 3 below will be represented by a probability space ( $\boldsymbol{S}_{s u}, \Gamma_{s u}$, $\boldsymbol{p}_{\text {su }}$ ), where the subscript "su" is used as a designator for "subjective”. The probability space $\left(\boldsymbol{S}_{s u}, \Gamma_{s u}, \boldsymbol{p}_{s u}\right.$ ), consists of three elements: a set $\boldsymbol{S}$ that contains all possibilities that could occur in the particular universe under consideration; a collection $\Gamma$ of subsets of $S$ for which probability will be defined; and a function $\boldsymbol{p}$ that actually defines probability for the elements of $\Gamma$. When viewed in its most general form, an uncertainty analysis simply involves the determination of the distribution $\boldsymbol{y}$ for those results from the function $\boldsymbol{f}$ in Eq. 2. Furthermore, the distribution for $\boldsymbol{y}$ can be presented as a cumulative distribution function (CDF) or as a complementary cumulative distribution function (CCDF), which is simply one minus the CDF. The CCDF can be formally defined by the integral [30]:

$$
\operatorname{prob}(y>Y)=\int_{S_{s u}} \delta_{Y}[f(x)] d_{s u}(X) d V_{s u}
$$

where $\boldsymbol{p r o b}(\boldsymbol{y}>\boldsymbol{Y})$ is the probability that a value larger than $\boldsymbol{Y}$ will occur, $\boldsymbol{d}_{\boldsymbol{s u}}$ represents the density function corresponding to the distributions in Eq. 4 and hence to the probability space $\left(\boldsymbol{S}_{s u}, \Gamma_{s u}, \boldsymbol{p}_{s u}\right)$, the differential $d V_{s u}$ is selected for mnemonic purposes, because integration will typically be over a high-dimension (i.e., $\boldsymbol{n X}$ ) volume. When $\boldsymbol{X}$ and $\boldsymbol{f}$ are predefined, the uncertainty analysis is simple in concept and involves evaluation of the integral in Eq. 3 to obtain the CDF and CCDF.

$$
\delta_{Y}[f(x)]=\left\{\begin{array}{lll}
1 & \text { if } & f(x)>Y \\
0 & \text { if } & f(x)<Y
\end{array} \quad\right. \text { (Eq. 4) }
$$


Many different methods are available to evaluate the integral of Eq. 3 including Monte Carlo simulation [31], differential analysis [32], a response surface methodology [33], the Fourier amplitude sensitivity test (FAST) [34] [and the closely related Sobol variance decomposition [35]], and fast probability integration [36]. According to [30], a Monte Carlo simulation with Latin Hypercube Sampling (LHS) is the most broadly applicable approach to the propagation and analysis of uncertainty and often the only approach that is needed. In this study, a LHS method based on a Monte Carlo simulation algorithm was generated in MATLAB to evaluate the effect of the uncertain input material properties of the two prisms. 
Table 7. Characterization of the input variable distribution functions

\begin{tabular}{|c|c|c|c|c|c|c|c|}
\hline Parameter & Symbol & Mean & STD & $\begin{array}{l}\text { Lower } \\
\text { Bound }\end{array}$ & $\begin{array}{l}\text { Upper } \\
\text { Bound }\end{array}$ & Distribution & Unit \\
\hline \multicolumn{8}{|c|}{ Solid Bricks } \\
\hline Young's modulus & $E_{b}$ & 1007 & 80 & 900 & 1200 & Normal & $\mathrm{MPa}$ \\
\hline Poisson's ratio & $v_{b}$ & 0.2 & - & - & - & Deterministic & - \\
\hline $\begin{array}{l}\text { Compression initial } \\
\text { yield }\end{array}$ & $\sigma_{c 0 b}$ & 16.7 & 1.3 & 13.0 & 19.0 & Normal & $\mathrm{MPa}$ \\
\hline $\begin{array}{l}\text { Compression ultimate } \\
\text { stress }\end{array}$ & $\sigma_{c u b}$ & 21.5 & 0.6 & 20.0 & 23.0 & Normal & $\mathrm{MPa}$ \\
\hline Tension failure stress & $\sigma_{t 0 b}$ & 3.3 & 0.4 & 3.0 & 5.0 & Normal & $\mathrm{MPa}$ \\
\hline \multicolumn{8}{|c|}{ Concrete Hollow Blocks } \\
\hline Young's module & $E_{b}$ & 9200 & 4500 & 3800 & 22000 & Normal & $\mathrm{MPa}$ \\
\hline Poisson's ratio & $v_{b}$ & 0.2 & & & & Deterministic & - \\
\hline $\begin{array}{l}\text { Compression initial } \\
\text { yield }\end{array}$ & $\sigma_{C O b}$ & 32.7 & 2.3 & 28.0 & 35.0 & Normal & $\mathrm{MPa}$ \\
\hline $\begin{array}{l}\text { Compression ultimate } \\
\text { stress }\end{array}$ & $\sigma_{c u b}$ & 35.7 & 2.5 & 35.0 & 40.0 & Normal & $\mathrm{MPa}$ \\
\hline Tension failure stress & $\sigma_{t 0 b}$ & 6.5 & 0.4 & 5.0 & 7.0 & Normal & $\mathrm{MPa}$ \\
\hline \multicolumn{8}{|c|}{ Mortar Layers } \\
\hline Young's module & $E_{m}$ & 313 & 89 & 60 & 400 & Normal & $\mathrm{MPa}$ \\
\hline Poisson's ratio & $v_{m}$ & 0.15 & - & 0.05 & 0.25 & Uniform & - \\
\hline $\begin{array}{l}\text { Compression initial } \\
\text { yield }\end{array}$ & $\sigma_{c 0}$ & 6.2 & 0.3 & 5.0 & 6.5 & Normal & $\mathrm{MPa}$ \\
\hline $\begin{array}{l}\text { Compression ultimate } \\
\text { stress }\end{array}$ & $\sigma_{c u m}$ & 7.0 & 0.2 & 6.5 & 8.0 & Normal & $\mathrm{MPa}$ \\
\hline Tension failure stress & $\sigma_{t 0 m}$ & 3.6 & 0.1 & 3.0 & 4.0 & Normal & $\mathrm{MPa}$ \\
\hline
\end{tabular}




\section{Results and Discussion}

\subsection{LHS Simulation}

For each model, 200 LHS simulations were performed, and a set of stratified probabilistic distribution functions (PDF) of the maximum eccentric compressive strength was derived for the two prisms (see Table 8). The statistical results indicated that the applied load for model 1 was in the range between $85.8 \mathrm{kN}$ and $124.7 \mathrm{kN}$. For model 1 , the mean maximum compressive load value was equal to $104.1 \mathrm{kN}$ and $\mathrm{COV}$ was equal to 0.07 . For model 2, the mean value was equal to $47.9 \mathrm{kN}$ and $\mathrm{COV}$ was equal to 0.08 . The maximum of load value reached was equal to $62.6 \mathrm{kN}$; and its minimum value was equal to $41.1 \mathrm{kN}$. 
Table 8. Statistical summary of the model PDFs

\begin{tabular}{ccc} 
& 1 & 2 \\
\hline Model & Brick masonry prism & Concrete hollow block prism \\
\hline Maximum $(\mathrm{kN})$ & -124.7 & -62.6 \\
Median $(\mathrm{kN})$ & -106.3 & -47.2 \\
Minimum $(\mathrm{kN})$ & -85.8 & -41.1 \\
Mean $(\mathrm{kN})$ & -104.1 & -47.9 \\
COV & 0.07 & 0.08
\end{tabular}


Figure 15 shows the CDF for the two models based on the results in Table 2. This illustrates the range of predicted values of the maximum compressive strength at the point of failure for each prism. The range of results appears reasonable considering the uncertainty in determining material characteristics. To determine the maximum compressive load of each masonry prism, the acceptable probability level must be considered for design purposes. For instance, if the accepted probability was set to 0.95 , the results would correspond to $88.8 \mathrm{kN}$ for the brick prism and $43.3 \mathrm{kN}$ for the concrete hollow prism. However, for the purposes of the student challenge (a blind prediction), it was decided to consider the acceptable probability failure level at a lower value of 0.50 (the mean value). This corresponded to a maximum compression load equal to $104.1 \mathrm{kN}$ for the brick masonry prism and $47.9 \mathrm{kN}$ for the concrete hollow block prism. These values were reported to the IMC challenge committee without prior knowledge of the final result. 


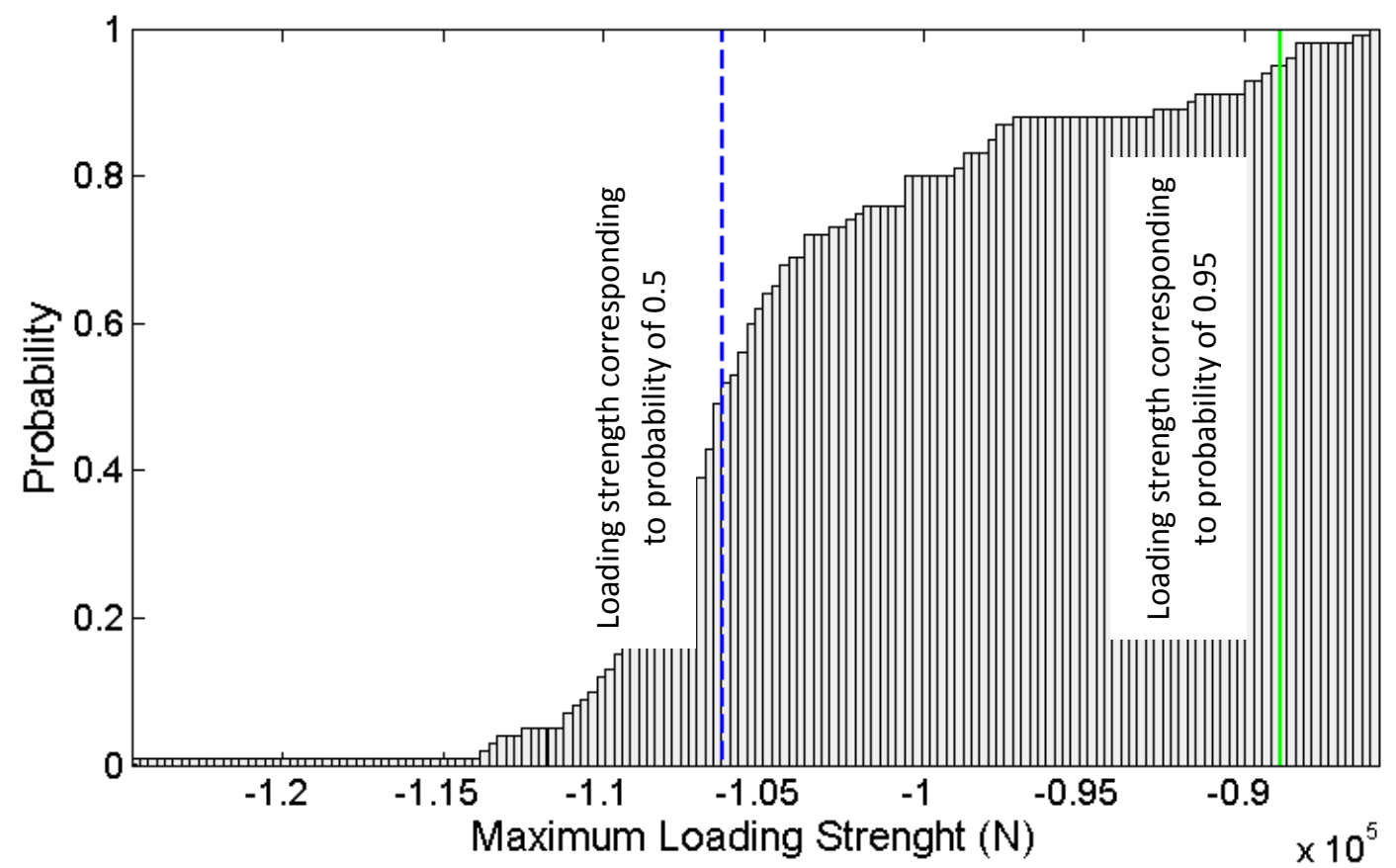

a)

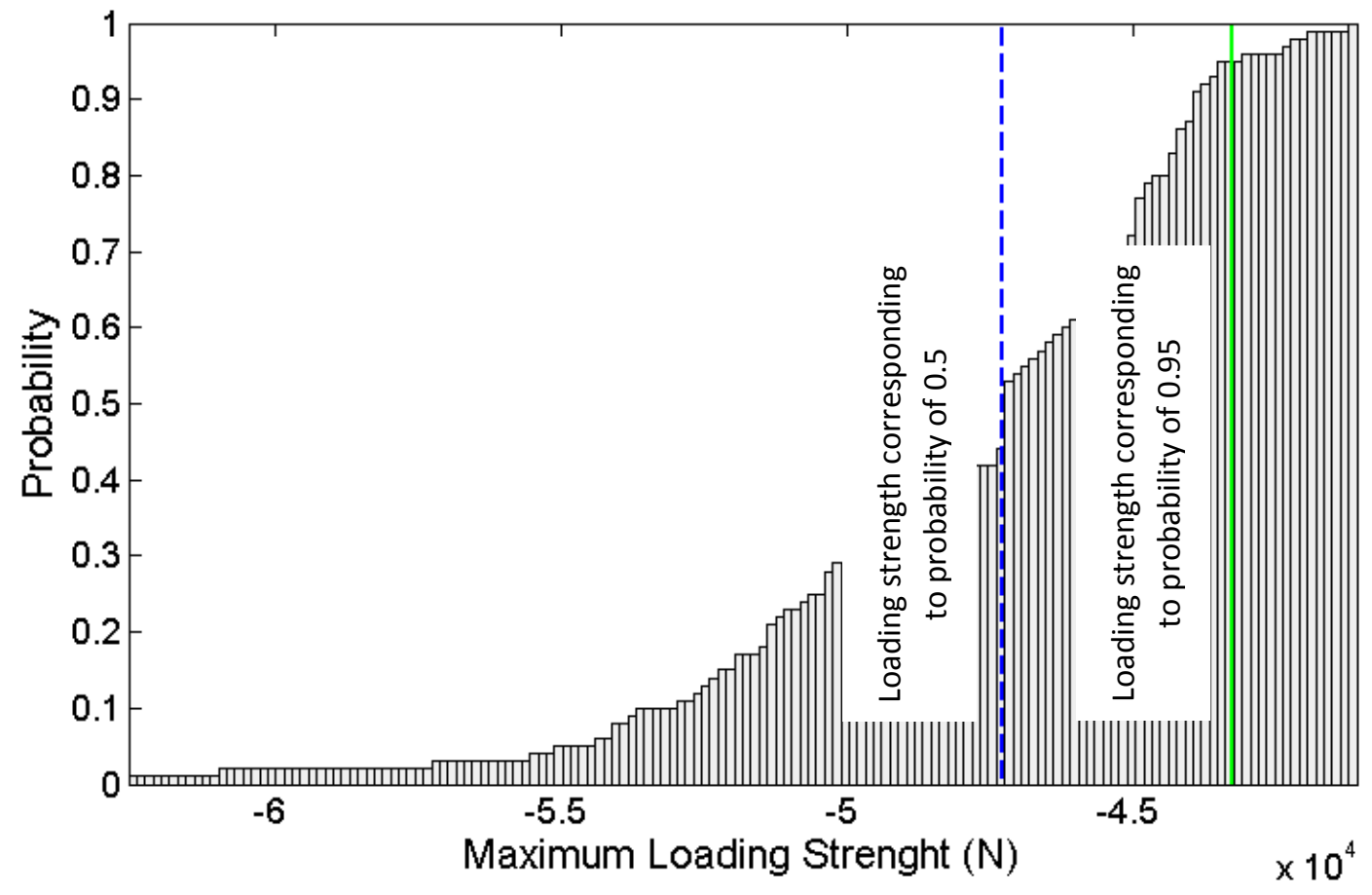

b)

Figure 15- CDFs of outputs: a) Brick masonry prism and b) Concrete hollow block prism (Continuous and dashed vertical lines correspond to the probability of 0.95 and 0.50 , respectively) 


\subsection{Experimental Results and Comparison}

Three specimens of each prism type were subsequently tested to determine the maximum compressive load during the IMC conference. The statistical summary of the experimental results is reported in Table 9. 
Table 9- Statistical summary of the Experimental Results

1

2

\begin{tabular}{ccc}
\hline Model & Brick masonry prism & Concrete hollow block prism \\
\hline Maximum $(\mathrm{kN})$ & -126.1 & -51.0 \\
Minimum $(\mathrm{kN})$ & -122.5 & -46.8 \\
Mean $(\mathrm{kN})$ & $-124.4(15 \%)^{*}$ & $-48.5(2 \%)^{*}$ \\
COV & 0.01 & 0.04
\end{tabular}

*Value in brackets indicate the error of result corresponded to the predictions 
A comparison of Table 9 to what was summarized from Class A prediction in Table 8 shows that the error of predictions of mean value for brick and hollow concrete bock prisms were $15 \%$ and $2 \%$, respectively. The root mean square deviation (RMSD) of the method for both types of prisms was just 2.2KN, which demonstrates the robustness of the probabilistic approach applied. The experimental results had, remarkably, a very low scatter, much lower than the predicted by the probabilistic model, despite the low number of specimens considered. Table 10 compares the predicted values with the EuroCode. The code is shown to be extremely conservative for both the brick and the concrete blocks by allowing less than $50 \%$ of the capacity in both cases. 
Table 10- Statistical summary of the Experimental Results

\begin{tabular}{lcc} 
& 1 & 2 \\
\hline \multicolumn{1}{c}{ Model } & Brick masonry prism & Concrete hollow block prism \\
\hline Class A prediction $(\mathrm{kN})$ & 104.1 & 47.9 \\
Experimental Result $(\mathrm{kN})$ & 124.4 & 48.5 \\
Maximum Ultimate Load by Euro Code $(\mathrm{kN})$ & 55.0 & 23.0
\end{tabular}




\section{Conclusions}

This paper outlined the probabilistic methodology implemented by University College Dublin’s Urban Modelling Group to predict the maximum compressive load of two masonry prisms. The experimental material data provided to all participants in the blind prediction were utilised to generate a probabilistic distribution function for each random input variable considered. In addition, the data were used to calibrate the numerical model to the experimental data. To generate more realistic results, the variance in values of material properties was applied in each individual brick and mortar joint conducting a semi-random field finite element analysis. For this purpose, the two prisms were simulated in ABAQUS commercial finite element software and were coupled with a Latin Hypercube Sampling algorithm generated in MATLAB. Loading was applied in a quasi-static manner, so as to simulate the loading process that was to be adopted during the testing phase.

The simulation results show that the probability distribution function for the brick masonry prism included a wide range of maximum loading values (between 85 and 124kN). For the concrete hollow prism, a range between 40 and $62 \mathrm{kN}$ was established. Comparing the experimental results to what was summarized from Class A prediction shows that the error of predictions of mean value for brick and hollow concrete bock prisms were just $15 \%$ and $2 \%$, respectively. The RMSD for both types of prisms was just $2.2 \mathrm{KN}$, which demonstrates the robustness of the probabilistic approach applied. The comparison also indicated that the design value reported to the IMC committee was safe and accurate, having observed less than the reported value for all experiments. All of observed results were remarkably in the range of predicted distribution function. The reported results were the best from the 26 participating teams. 


\section{ACKNOWLEDGEMENTS}

This work was sponsored with funding from the European Union's grant ERC StG 2012307836-RETURN. The experimental testing program and student blind competition was sponsored by the European Lime Association (EuLA).

\section{REFERENCES}

1. Challenge, I.S., Maximum Compressive Load of Prisms, 1st Testing report 2014, University of Minho, School of Engineering.

2. Challenge, I.S., Maximum Compressive Load of Prisms, 2nd Testing report 2014, University of Minho, School of Engineering.

3. Lambe, T., Predictions in soil engineering. Geotechnique, 1973. 23(2): p. 151-202.

4. Brencich, A. and G.d. Felice, Brickwork under eccentric compression: Experimental results and macroscopic models. Construction and Building Materials, 2009. 23(5): p. 1935-1946.

5. CEN, E., Eurocode 6 - Design of masonry structures, in Part 1-1: General rules for reinforced and unreinforced masonry structures 2005.

6. MSJC, M.S.J.C., Building code requirements for masonry structures, 2013, American Concrete Institute, Structural Engineering, Institute of the American Society of Civil Engineers, The Masonry Society: Detroit.

7. Zucchini, A. and P.B. Lourenço, Mechanics of masonry in compression: Results from a homogenisation approach. Computers \& Structures, 2007. 85(3-4): p. 193-204.

8. Ahmad, A.H. and O.C. Ambrose, Compressive behavior of concrete masonry prisms. Journal of Structural Engineering, 1986. 112(3): p. 605-613.

9. Kaushik, H.B., D.C. Rai, and S.K. Jain, Stress-strain characteristics of clay brick masonry under uniaxial compression. Journal of materials in Civil Engineering, 2007. 19(9): p. 728-739.

10. Bennett, R.M., K.A. Boyd, and R.D. Flanagan, Compressive properties of structural clay tile prisms. Journal of Structural Engineering, 1997. 123(7): p. 920-926.

11. Dayaratnam, P., Brick and reinforced brick structures. 1987: South Asia Books.

12. Binda, L., A. Fontana, and G. Frigerio, Mechanical behaviour of brick masonries derived from unit and mortar characteristics. Brick and Block Masonry(8 th IBMAC) London, Elsevier Applied Science, 1988. 1: p. 205-216.

13. Ewing, B.D. and M.J. Kowalsky, Compressive behavior of unconfined and confined clay brick masonry. Journal of Structural Engineering, 2004. 130(4): p. 650-661.

14. Hendry, A.W., Structural masonry. 1990: Scholium International.

15. McNary, W.S. and D.P. Abrams, Mechanics of masonry in compression. Journal of Structural Engineering, 1985. 111(4): p. 857-870.

16. Naraine, K. and S. Sinha, Behavior of brick masonry under cyclic compressive loading. Journal of Structural Engineering, 1989. 115(6): p. 1432-1445. 
17. Rai, D.C. and S.C. Goel, Seismic strengthening of unreinforced masonry piers with steel elements. Earthquake spectra, 1996. 12(4): p. 845-862.

18. Sarangapani, G., B. Venkatarama Reddy, and K. Jagadish, Brick-mortar bond and masonry compressive strength. Journal of materials in civil engineering, 2005. 17(2): p. 229-237.

19. Tomazevic, M. and R. Velochovsky, Some aspects of experimental testing of seismic behavior of masonry walls and models of masonry buildings. Earthquake Engineering and Structural Dynamics, 1992. 21(11): p. 945-963.

20. $\mathrm{ACl}$, Commentary on specification for masonry structures, in Manual of concrete practice2004: Detroit, USA.

21. Vermeltfoort, A.T. Compression properties of masonry and its components. in Proceedings of 10th international brick and block masonry conference, University of Calgary, Canada. 1994.

22. Blackard, B., et al. Failure issues of brick masonry. in Proceedings of the Sixth International Conference on Fracture Mechanics of Concrete and Concrete Structures. 2007.

23. Pina-Henriques, J. and P.B. Lourenço, Masonry compression: a numerical investigation at the meso-level. Engineering computations, 2006. 23(4): p. 382-407.

24. Dobruschin, P., The description of a random field by means of conditional probabilities and conditions of its regularity. Theory of Probability \& Its Applications, 1968. 13(2): p. 197-224.

25. Sudret, B. and A. Der Kiureghian, Stochastic finite element methods and reliability: a state-of-theart report. 2000: Department of Civil and Environmental Engineering, University of California.

26. SIMULIA, ABAQUS, 2010.

27. MathWorks, MATLAB, 2013.

28. Lubliner, J., et al., A plastic-damage model for concrete. International Journal of solids and structures, 1989. 25(3): p. 299-326.

29. Mohamad, G., P.B. Lourenço, and H.R. Roman, Mechanics of hollow concrete block masonry prisms under compression: Review and prospects. Cement and Concrete Composites, 2007. 29(3): p. 181-192.

30. Helton, J.C. and F.J. Davis, Latin hypercube sampling and the propagation of uncertainty in analyses of complex systems. Reliability Engineering \& System Safety, 2003. 81(1): p. 23-69.

31. Halton, J.H., A retrospective and prospective survey of the Monte Carlo method. SIAM, 1970. 12(1): p. 1-63.

32. Eberhard, P. and C. Bischof, Automatic differentiation of numerical integration algorithms. Mathematics of Computation, 1999. 68(226): p. 717-731.

33. Myers, R.H., A.I. Khuri, and W. Carter Jr, Response surface methodology: 1966-1988. Technometrics, 1989. 31(2): p. 137-157.

34. McRae, G.J., J.W. Tilden, and J.H. Seinfeld, Global sensitivity analysis-a computational implementation of the Fourier amplitude sensitivity test (FAST). Comput Chem Engng, 1981. 6(1): p. 15-25.

35. Sobol', I.y.M., On sensitivity estimation for nonlinear mathematical models. Matematicheskoe Modelirovanie, 1990. 2(1): p. 112-118.

36. Wu, Y.-T., DEMONSTRATION OF A NEW, FAST PROBABILITY INTEGRATION METHOD FOR RELIABILITY ANALYSIS. Journal of engineering for industry, 1987. 109(1): p. 24-28. 